\title{
ASCARIASIS AND COEXISTANT STONE IN COMMON BILE DUCT IN POST CHOLECYSTECTOMY POST CHOLEDOCHOLITHOTOMY WOMAN: A CASE REPORT
}

Khalid Mahmood ${ }^{1}$, Mahendra Singh 2 , Pradeep Jaiswal ${ }^{3}$, Krishna Gopal ${ }^{4}$, Vibhuti Bhusan ${ }^{5}$, S. S. Haque ${ }^{6}$, Sanjay Kumar7, Vijayanand Choudhary8, Sangeeta Pankaj ${ }^{9}$

\section{HOW TO CITE THIS ARTICLE:}

Khalid Mahmood, Mahendra Singh, Pradeep Jaiswal, Krishna Gopal, Vibhuti Bhusan, S. S. Haque, Sanjay Kumar, Vijayanand Choudhary, Sangeeta Pankaj. "Ascariasis and coexistant stone in common bile duct in postCholecystectomy Post Choledocholithotomy Woman: A Case report". Journal of Evolution of Medical and Dental Sciences 2014; Vol. 3, Issue 61, November 13; Page: 13621-13624, DOI: 10.14260/jemds/2014/3818

ABSTRACT: Ascariasis is one of the commonest infections in Asia. Biliary ascariasis is a serious presentation of ascariasis which can result in life threatening complications including cholangitis, choledocholithiasis, Liver abscess, and Pancreatitis. We present a case of female from north Bihar who presented to us with biliary ascariasis and concomitant stone. Diagnosis was established by abdominal ultrasonography. Choledocholithotomy done and a live round worm with two biliary stone extracted.

KEYWORDS: Biliary ascarisis, Choledocholithiasis, Choledocholithotomy.

INTRODUCTION: Ascariasis is one of common helminthic disease in human. ${ }^{1}$ It is widely distributed in tropical and sub-tropical regions where there is insufficient sanitation, hygiene, and education regarding these parasite. ${ }^{2}$ In endemic areas $30 \%$ of adults and $60-70 \%$ of children harbor the adult worm. ${ }^{3}$ Worldwide ascariasis is second to gallstone as cause of acute biliary symptoms. ${ }^{4}$ Common presentation of Biliary ascariasis include bilary colic, acute cholangitis, Obstructive jaundice, Choledocholithiasis and cholecystitis. ${ }^{5}$

Here we present a case of a female from north Bihar, who presented with pain upper abdomen, nausea and excess gas formation that had undergone Cholycystectomy and Cholidocholithotomy two year back.

CASE REPORT: A 50 years old female from West Champaran district of north Bihar presented with pain upper abdomen two month back. She was suffering from pain upper abdomen, nausea and excess gas formation since one year. Pain aggravated in severity thrice in year which needs hospitalization. Patient has undergone cholecystectomy and cholidocholithotomy two year back. Initial work -up showed elevated SGPT, serum alkaline phosphtase, leucocytosis with normal serum bilirubin. Ultrasound of abdomen revealed dilated Common bile duct $(10 \mathrm{~mm})$ with two stone of size $6 \mathrm{~mm}$ and $7 \mathrm{~mm}$ size.

Patient was treated with Intravenous fluid, antiemetic, antibiotic and ursodecholic acid. Patient's symptoms improved. Ten days back patient again came with severe pain abdomen and nausea. Again ultrasound of abdomen was done which revealed round worm with stone in Common bile duct. Choledocholithotomy was done. One living round worm of about $15 \mathrm{~cm}$ in length was removed along with two stone of size $7 \mathrm{~mm}$ and $9 \mathrm{~mm}$. (Figure-1) 


\section{CASE REPORT}

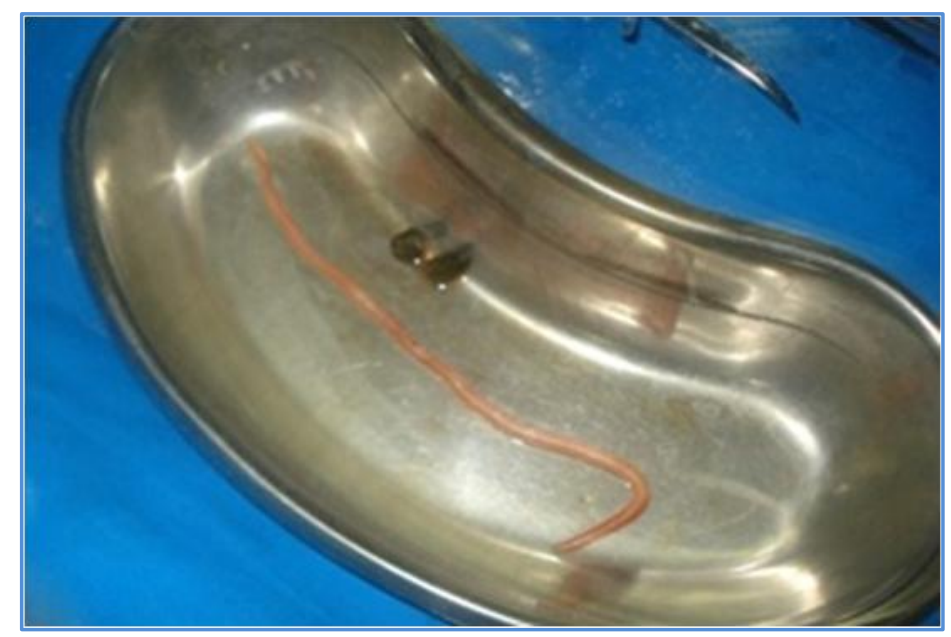

Fig. 1: Round worm along with stone

DISCUSSION: Ascaris Lumbricoides, the roundworm, is the most common parasite that infect human gastrointestinal tract. It has a complex life cycle, which is completed in intestines and lungs and finally in jejunum. Adult worm may grow up to $40 \mathrm{~cm}$ in length and live for two years. ${ }^{6}$ The worms have a tendency to explore small opening. When in the duodenum they may enter the ampullary orifice and advance into bile and hepatic duct, ultimately causing hepatobiliary ascariasis. ${ }^{7}$ Hepatobiliary ascariasis is more common in females and after cholelithiasis,is the second most common cause of acute biliary symptoms world-wide. ${ }^{8}$ Common presenting symptom is pain. Fever, jaundice, nausea and vomiting are less frequent. ${ }^{9}$

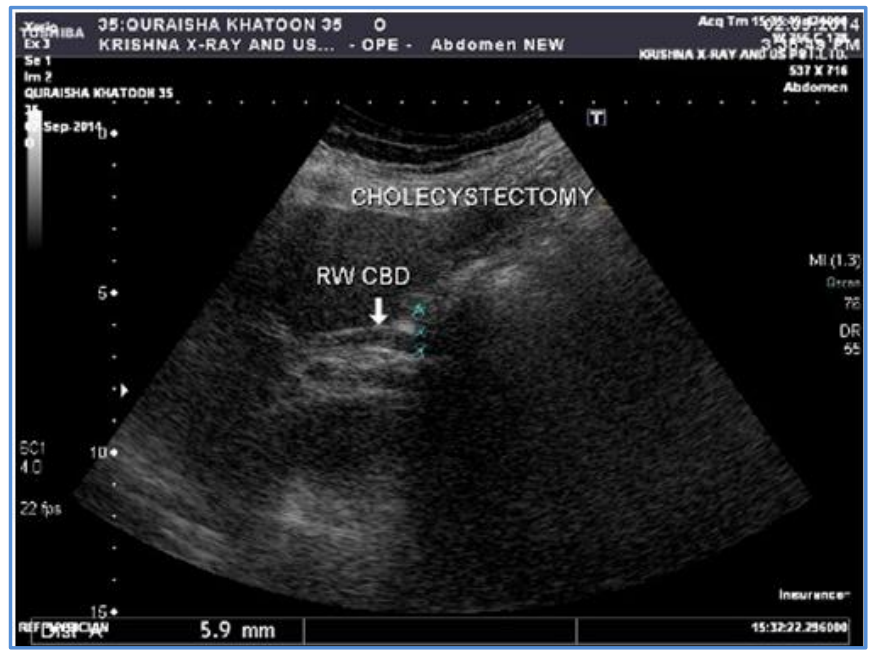

\section{Fig. 2: Round worm with stone in C B D}

Previously diagnosis of ascariasis migrating into biliary tract was difficult and usually made at laprotomy. ${ }^{10}$ Nowadays. Abdominal ultrasound is imaging modality of choice of hepatobiliary ascariasis. 


\section{CASE REPORT}

Movement of worms can also be seen. ${ }^{11}$ Abdominal ultrasonography has been shown to have a high diagnostic accuracy as a non-invasive procedure. ${ }^{12}$ The characteristic sonographic feature of worms in the common bile duct is a long linear parallel echogenic strip, usually without acoustic shadow. ${ }^{13}$ Other favorable imaging modalities include MRI and MRCP. Axial image in T weighted sequence shows a dot hypo intense signal in CBD around which the bile signals are hyperintense.MR cholangiography shows intra ductal worms as linear hypo intense filling defects. ${ }^{14}$

ERCP is very useful investigational modality not only because its major therapeutic potential but also it permits direct visualization of the worms in the duodenum and across the papilla and helps in radiographic demonstration of the worms in the biliary tract. The worms in the duct appear as smooth, linear filling defects with tapering ends. ${ }^{15}$

Various therapeutic modalities can be applied in management of hepatobiliary ascariasis, including conservative approach, endoscopic extraction and surgical intervention. Majority of the patients with uncomplicated biliary ascariasis will respond to conservative management.14 Intervention is required in a small proportion of patients under the following circumstances. ${ }^{16}$

1. Those critically ill with pyogenic cholangitis or unresolving cholecystitis.

2. Worm fails to leave the biliary tree within four weeks as by that time they are presumed to be dead and need extraction.

3. Worms's co-existent with stones.

4. Associated liver abscess.

In our case patient presented with concomitant stone and worm in CBD. Patient underwent open choledocolithotomy and a live worm about $15 \mathrm{~cm}$ long along with two stones $7 \mathrm{~mm}$ and $9 \mathrm{~mm}$ extracted. Post op period was uneventful. T tube removed after fourteen days. We have done surgical intervention on patient's demand. However endoscopic extraction is one of the options. Laparoscopic extraction of worms and stone has been done successfully. ${ }^{17}$

CONCLUSION: CBD stone with ascariasis should be considered in patient complaining of pain abdomen and other biliary symptoms in post-cholecystectomy and post choledocolithotomy patients. Carefully done abdominal ultrasonography reveal Biliary ascariasis and co existent stone with high accuracy.

\section{REFERENCES:}

1. P fefferman R: Ascariasis of biliary System. Arch of Surgery 1972; 195: 118.

2. Khan A, Bhasin S, Bhajat R, Chrungu R. An unusual Presentation of biliary ascariasis. Jk Science Journal of Medical Education and Reserch 2007; 9: 35-36.

3. Khuroo M S, Mahajan R, Zargar SA, Javid G, Sapru S, Prevalence of biliary tract diseases in India A sonographic study in adult population Kashmir Gut 1989: 30: 201-205.

4. Osman M, Lasten SB, Taleet ES et al Biliary parasites Digestive Surg 1998; 15: 287-96CB.

5. Baba A A, Shera A H, Bhat M A, Hakim S, Sheikh K A, Shah O J. Management of Biliary ascariasis in children living in an endemic area. Eur J Pediatric surg. 2010; 20: 187- 190.

6. Zargar S A, Lehan B A, Javid G et al. Endoscopic management of early postoperative biliary ascariasis in patient with biliary tract surgery. World J Surg 2004 Jul; 28 (7): 712-15.

7. Shah o, Zargar S, Robbani I, Biliary ascariasis: A Review. World J. Surgery 2006; 30 1500-1506. 
8. Hussain S, Islam A, Ahmad S, Mohsen A, Khanum F. Biliary ascariasis: An experience of 47 cases. Bangladesh Medical college journal 2010; 15: 59-62.

9. Satapathy S, Shiftech A, Kadam J, Friedman B, Ceruli M,Yang S.A case report: Acute Cholangitis Secondary to Biliary Ascariasis. Practical gasteroenterology 2011; 35: 25-28.

10. Chang CC. Han CT Biliariy ascarasis in childhood. Chinise medical journal 1966; 85: 167-71.

11. Abuhasna Said MD, Akbar Mohammed, Maysoon M, Masood UR, Amer AJ: Biliary ascariasis leading to choledocholithiasis, Cholengitis, hepatic abscess and gram negative scepticemia. Anaesthesia Pain and Intensive care, 2012; 16 (2): 186-88.

12. Mukhopadhay M. Biliary ascariasis in the Indian Subcontinent: a study of 42 cases. Saudi Journal of gastroenterology 2009, 15: 121-124.

13. Sharma M. Echogenic shadow in common bile duct. Diagnosis: Biliary ascariasis; Gastroenterology 2011; 141: 14-15.

14. Khan A S.,Bhowmic B, Hakim HAN, Islam M A. Outcome of conservative Management in biliary Ascariasis - A study of 98 cases. J Dhaka Med Coll.2010; 19: 203- 206.

15. Rana S, Bhasin D, Nanda M, Singh K Parasitic infestations of the Biliary TractCurrent Gynaecology Reports 2007; 9: 156-164.

16. Alam S, Mustafa G, Rahman S, Kabir SA, Rashid Ho, Khan M. Comparative study on presentation of Biliary ascariasis with dead and living worms. The Saudi Journal of Gastroenterology 2010; 16: 203-206.

17. Yoshihara S, Toyoki Y, Takahasi O, Sasaki M. Laparoscopic treatment for biliary ascariasis. Surgical Laparoscopy, Endoscopy and percutaneous techniques, 2000; 10: 103-105.

\section{AUTHORS:}

1. Khalid Mahmood

2. Mahendra Singh

3. Pradeep Jaiswal

4. Krishna Gopal

5. Vibhuti Bhusan

6. S. S. Haque

7. Sanjay Kumar

8. Vijayanand Choudhary

9. Sangeeta Pankaj

\section{PARTICULARS OF CONTRIBUTORS:}

1. Consultant Surgeon, Department of General Surgery, IGIMS.

2. Professor \& Head Urology, Department of General Surgery, IGIMS.

3. Assistant Professor, Department of General Surgery, IGIMS.

4. Assistant Professor, Department of General Surgery, IGIMS.

5. Assistant Professor, Department of General Surgery, IGIMS.
6. Biochemist, Department of General Surgery, IGIMS.

7. Additional Professor, Department of Community Medicine, IGIMS.

8. Associate Professor, Department of Histopathology, IGIMS.

9. Associate Professor, Department of Gynaecological Oncology, IGIMS.

\section{NAME ADDRESS EMAIL ID OF THE CORRESPONDING AUTHOR:}

Dr. Sangeeta Pankaj,

Associate Professor,

Department of Gynaecological Oncology,

RCC, IGIMS,

Sheikhpura, Patna.

Email: sangeetapankaj@yahoo.co.in

Date of Submission: 02/10/2014.

Date of Peer Review: 03/10/2014.

Date of Acceptance: 10/11/2014.

Date of Publishing: 13/11/2014. 